\title{
Canonical and non-canonical WNT signaling in cancer stem cells and their niches: Cellular heterogeneity, omics reprogramming, targeted therapy and tumor plasticity (Review)
}

\author{
MASARU KATOH \\ Department of Omics Network, National Cancer Center, Tokyo 104-0045, Japan
}

Received July 30, 2017; Accepted September 15, 2017

DOI: $10.3892 /$ ijo.2017.4129

\begin{abstract}
Cancer stem cells (CSCs), which have the potential for self-renewal, differentiation and de-differentiation, undergo epigenetic, epithelial-mesenchymal, immunological and metabolic reprogramming to adapt to the tumor microenvironment and survive host defense or therapeutic insults. Intra-tumor heterogeneity and cancer-cell plasticity give rise to therapeutic resistance and recurrence through clonal replacement and reactivation of dormant CSCs, respectively. WNT signaling cascades cross-talk with the FGF, Notch, Hedgehog and TGF $\beta / B M P$ signaling cascades and regulate expression of functional CSC markers, such as CD44, CD133 (PROM1), EPCAM and LGR5 (GPR49). Aberrant canonical and non-canonical WNT signaling in human malignancies, including breast, colorectal, gastric, lung, ovary, pancreatic, prostate and uterine cancers, leukemia and melanoma, are involved in CSC survival, bulk-tumor expansion and invasion/ metastasis. WNT signaling-targeted therapeutics, such as anti-FZD1/2/5/7/8 monoclonal antibody (mAb) (vantictumab), anti-LGR5 antibody-drug conjugate (ADC) (mAb-mc-vcPAB-MMAE), anti-PTK7 ADC (PF-06647020), anti-ROR1 $\mathrm{mAb}$ (cirmtuzumab), anti-RSPO3 mAb (rosmantuzumab), small-molecule porcupine inhibitors (ETC-159, WNT-C59 and WNT974), tankyrase inhibitors (AZ1366, G007-LK, NVP-TNKS656 and XAV939) and $\beta$-catenin inhibitors (BC2059, CWP232228, ICG-001 and PRI-724), are in clinical trials or preclinical studies for the treatment of patients with WNT-driven cancers. WNT signaling-targeted therapeutics are applicable for combination therapy with BCR-ABL, EGFR, FLT3, KIT or RET inhibitors to treat a subset of tyrosine kinase-driven cancers because WNT and tyrosine kinase signaling cascades converge to $\beta$-catenin for the maintenance and expansion of CSCs. WNT signaling-targeted
\end{abstract}

Correspondence to: Dr Masaru Katoh, Department of Omics Network, National Cancer Center, 5-1-1 Tsukiji, Chuo-ward, Tokyo 104-0045, Japan

E-mail: mkatoh-kkr@umin.ac.jp

Key words: APC, CTNNB1, FGFR1, FGFR2, PI3K, RNF43, RSPO2, WNT2B, WNT5A, YAP therapeutics might also be applicable for combination therapy with immune checkpoint blockers, such as atezolizumab, avelumab, durvalumab, ipilimumab, nivolumab and pembrolizumab, to treat cancers with immune evasion, although the context-dependent effects of WNT signaling on immunity should be carefully assessed. Omics monitoring, such as genome sequencing and transcriptome tests, immunohistochemical analyses on PD-L1 (CD274), PD-1 (PDCD1), ROR1 and nuclear $\beta$-catenin and organoid-based drug screening, is necessary to determine the appropriate WNT signalingtargeted therapeutics for cancer patients.

\section{Contents}

1. Introduction

2. Canonical WNT signaling in CSCs and their niches

3. Non-canonical WNT signaling in CSCs and their niches

4. Anti-CSC mono-therapy targeting WNT signaling cascades

5. Anti-CSC combination therapy using WNT signaling targeted drugs

6. Omics monitoring for WNT signaling-targeted therapy

7. Conclusion

\section{Introduction}

Cancer stem cells (CSCs), which show the potential for selfrenewal and differentiation, have been identified in a variety of human cancers based on their tumor initiating potential in vivo (1-3). Clonal expansion of a minor CSC population with a drug-resistant mutation causes early recurrence, whereas reactivation of dormant CSCs into cycling CSCs owing to tumor plasticity leads to late relapse (4-6). CSCs or bulk tumor cells undergo epigenetic reprogramming (7), epithelial-mesenchymal reprogramming [epithelial-to-mesenchymal transition (EMT) and mesenchymal-to-epithelial transition (MET)] $(8,9)$, immunological reprogramming (immuno-editing) $(10,11)$ and metabolic reprogramming (12) to adapt to the tumor microenvironment, which is collectively defined here as 'omics reprogrammming' (Fig. 1). Since cycling CSCs that depend on aerobic glycolysis converge into quiescent mesenchymal CSCs through omics reprogramming to survive therapeutic insult for later recurrence, CSC targeting is necessary to avoid relapse 
after cancer therapy and improve the cost-effectiveness ratio of cancer precision medicine.

CD44, CD133 (PROM1), EPCAM and LGR5 (GPR49) are representative cell-surface markers of CSCs (2,13-16). LGR5, encoding an R-spondin (RSPO) receptor, is a target gene of the canonical WNT/ $\beta$-catenin signaling cascade in quiescent as well as cycling stem cells, whereas CD44 and CD133 are further upregulated by WNT and RSPO signals in LGR5 ${ }^{+}$ cycling stem/progenitor cells (17-19). EPCAM can potentiate the canonical WNT/ $\beta$-catenin signaling cascade through intra-membrane proteolysis and subsequent nuclear translocation of its intracellular C-terminal domain (20). WNT signaling cascades cross-talk with the FGF, Notch, Hedgehog and TGF $\beta / B M P$ signaling cascades to constitute the stem cell signaling network, which regulates expression of functional CSC markers (21-24).

The WNT family proteins transduce signals through the Frizzled (FZD) and LRP5/6 receptors to the WNT/ $\beta$-catenin and WNT/STOP (stabilization of proteins) signaling cascades (also known as the canonical WNT signaling cascades) and through the FZD and/or ROR1/ROR2/RYK receptors to the WNT/PCP (planar cell polarity), WNT/RTK (receptor tyrosine kinase) and WNT/Ca ${ }^{2+}$ signaling cascades (also known as the non-canonical WNT signaling cascades) (21,25-29). The canonical WNT/ $\beta$-catenin signaling cascade is involved in self-renewal of stem cells and proliferation or differentiation of progenitor cells (30-33), whereas non-canonical WNT signaling cascades are involved in maintenance of stem cells, directional cell movement or inhibition of the canonical WNT signaling cascade (34-37). Both canonical and non-canonical WNT signaling cascades play key roles in the development and evolution of CSCs.

By contrast, tumors consist of heterogeneous populations of cancer cells and non-cancerous stromal/immune cells $(38,39)$. Intra-tumor heterogeneity of cancer cells is caused by the evolution of CSCs based on epigenetic and genetic alterations (40-42), as well as the differentiation of CSCs into bulk tumor cells (1-3), niche-like cancer supporting cells (43), endothelial-like cancer cells (44) and fibroblast-like cancer cells (45). On the other hand, intra-tumor heterogeneity of non-cancerous stromal/immune cells is orchestrated by and reciprocally orchestrates CSCs and their descendants (39,45-47). Interaction and co-evolution of CSCs and niche cells are driving forces of cancer progression. Herein, canonical and non-canonical WNT signaling in CSCs will be described, with a focus on the heterogeneity of cancer and stromal/immune cells in the tumor microenvironment; then, anti-CSC mono- and combination therapies using WNT signaling-targeted therapeutics will be reviewed with emphases on omics reprogramming and tumor plasticity.

\section{Canonical WNT signaling in CSCs and their niches}

Canonical WNT signaling through the FZD-LRP5/6 receptor complex leads to de-repression of $\beta$-catenin as well as STOPtarget proteins, such as ATOH1, CCND1 (Cyclin D1), FOXM1, MYC (c-MYC), NRF2 (NFE2L2), PLK1, SMAD1/3/4, SNAI1 (Snail) and YAP/TAZ, from proteasomal degradation induced by GSK-3 $\beta$-dependent phosphorylation and subsequent ubiquitylation (27-29,48) (Fig. 2). $\beta$-catenin stabilization and subsequent nuclear translocation leads to transcriptional activation of $\beta$-catenin-TCF/LEF target genes, such as ATOH1, CCND1, CD44, FGF20, JAG1, LGR5, MYC and SNAI1, although transcriptional outputs of the $\mathrm{WNT} / \beta$-catenin signaling cascade are determined in a cellular contextdependent manner (e.g., epigenetic status of target genes and activities of other transcriptional regulators). ATOH1, CCND1, MYC and SNAI1 are upregulated transcriptionally and posttranslationally by the $\beta$-catenin and STOP signaling cascades, respectively. Canonical WNT signals control cell fate and function through transcriptional and post-translational regulation of the omics network.

Canonical WNT signaling in CSCs is activated by WNT2B, WNT3 and other canonical WNT ligands derived from cancerous supporting cells or non-cancerous stromal cells (49-52), as well as genetic alterations in the canonical WNT/ $\beta$-catenin signaling components, such as EIF3E-RSPO2 fusions, PTPRK-RSPO3 fusions, gain-of-function mutations in the CTNNB1 ( $\beta$-catenin) gene and loss-of-function mutations in the APC, AXIN1, AXIN2, RNF43 and ZNRF3 genes (29,53-55). Canonical WNT signals increase the LGR5 receptor level on CSCs for the maintenance of the canonical WNT responsive state but also upregulate AXIN2, DKK1, NOTUM, RNF43 and ZNRF3 for negative feedback regulation (18-21,29). Loss-of-function mutations in the APC, AXIN2, $R N F 43$ and ZNRF3 genes release CSCs from the constraints of the negative feedback regulation.

Canonical WNT signals can directly promote CSC proliferation through upregulation of CCND1, FOXM1, MYC and YAP/TAZ as described above. By contrast, canonical WNT signaling in CSCs induces expression and secretion of growth factors, such as FGFs, KIT ligand (KITLG or SCF) and VEGF (VEGFA), to fine-tune the tumor microenvironment $(18,21,29)$. For example, MET (HGF receptor) is upregulated in human basal-like breast cancers with TP53 mutations as well as mouse basal-like breast tumors with compound gain-offunction Ctnnbl mutation and homozygous Tp53 deletion (56), and combined activation of the canonical WNT/ $\beta$-catenin and HGF/MET signaling cascades induces SHH upregulation in mouse mammary CSCs and subsequent activation of cancerassociate fibroblasts for the synergistic proliferation of CSCs and cancer-associate fibroblasts (57).

Together, these findings indicate that canonical WNT signaling is involved in the maintenance and expansion of CSCs through direct effects on CSCs themselves and indirect effects via CSC-stromal/immune interactions.

\section{Non-canonical WNT signaling in CSCs and their niches}

Non-canonical WNT signaling through FZD receptors and/ or ROR1/ROR2/RYK co-receptors activates the PCP, RTK or $\mathrm{Ca}^{2+}$ signaling cascades (Fig. 2).

Non-canonical WNT/PCP signaling through FZD receptors and Dishevelled (DVL) adaptor proteins regulates the coordinated cellular orientation within an epithelial plane, collective cell movements during gastrulation and neurulation stages of embryogenesis and directional cell movement during invasion and metastasis of cancer cells (58-62). WNT/PCP signals are converted to actin cytoskeletal dynamics via the small G-proteins RAC and RHO (Fig. 2), and then, RAC and RHO 


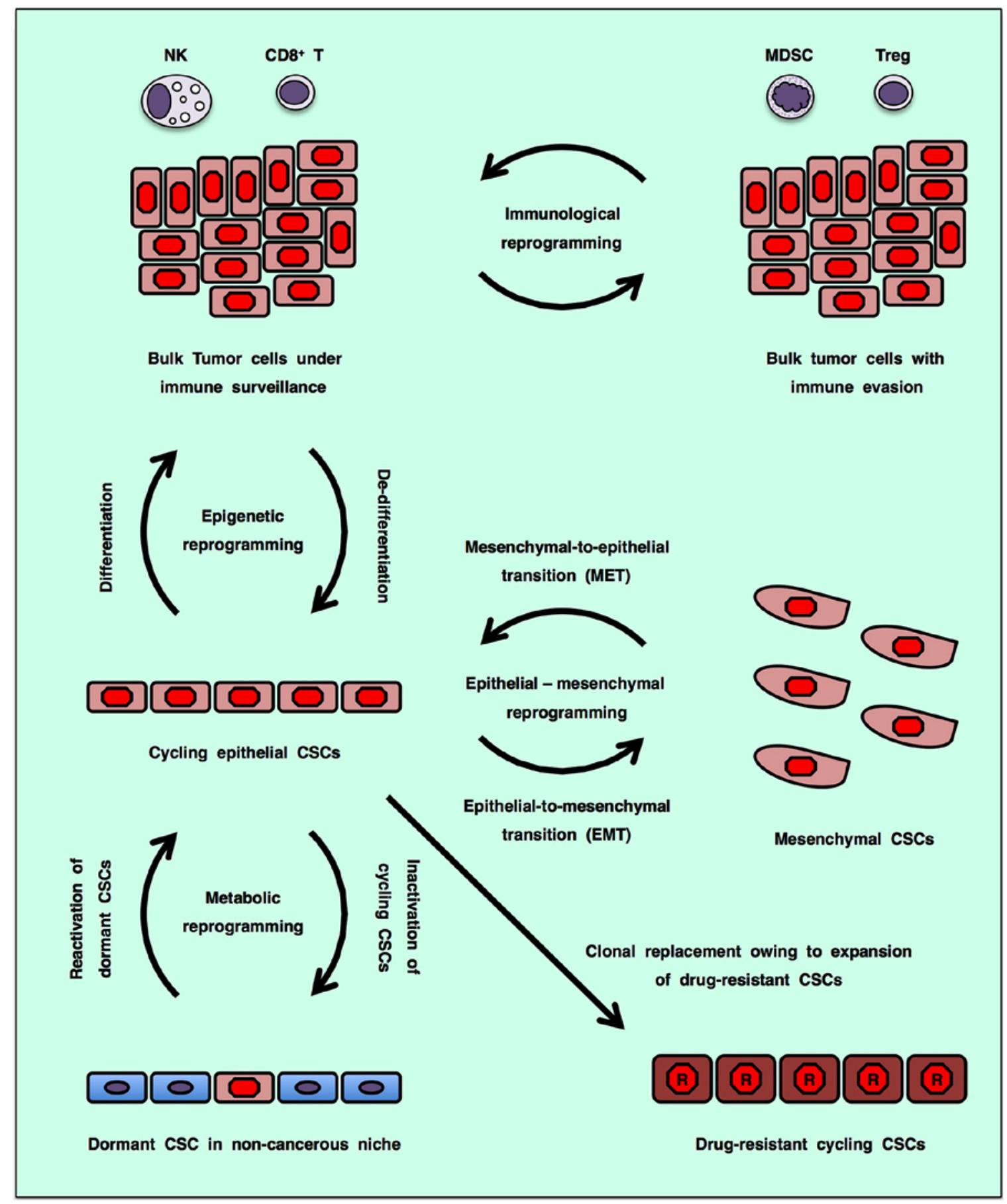

Figure 1. Therapeutic resistance owing to evolution and plasticity of cancer stem cells (CSCs). CSCs with self-renewal, differentiation and de-differentiation potentials undergo omics reprogramming, such as epigenetic reprogramming, immuno-editing (immunological reprogramming), two-way shifts between epithelial and mesenchymal states (epithelial-mesenchymal reprogramming) and two-way shifts between aerobic glycolysis and oxidative phosphorylation in the tricarboxylic acid cycle (metabolic reprogramming). Genetic or epigenetic evolution of CSCs gives rise to a repertoire of drug-resistant CSCs, which cause early recurrence through clonal expansion of drug-resistant CSCs replacing drug-sensitive bulk tumors. By contrast, the plasticity of CSCs with omics reprogramming potential gives rise to dormant CSCs to survive host defense or therapeutic insult, which cause late relapse through reactivation of dormant CSCs into cycling CSCs. CSC-targeted therapeutics are necessary to avoid drug resistance or recurrence after anticancer therapy. MDSC, myeloid-derived suppressor cell; NK, natural killer cell; Treg, regulatory T cell.

activate JNK-dependent transcription and YAP/TAZ-dependent transcription, respectively (63-66). WNT/PCP signaling regulates actin cytoskeletal dynamics, directional cell movement and JNK- or YAP/TAZ-dependent transcription.

Non-canonical WNT signaling through RTKs, such as ROR1, ROR2 and RYK, activates the PI3K-AKT signaling cascade (29,67-69). ROR1 and ROR2, with the extracellular
WNT-binding FZD-like domain, are homologous to MUSK, NTRK1, NTRK2, NTRK3, DDR1 and DDR2 in their cytoplasmic tyrosine kinase domain, whereas RYK with an extracellular WNT-binding WIF domain is homologous to AXL, EGFR, ERBB2, ERBB3, ERBB4, MET, MERTK, MST1R and TYRO3 in its cytoplasmic tyrosine kinase domain (39,70-73). ROR1 and ROR2 are atypical RTKs that 


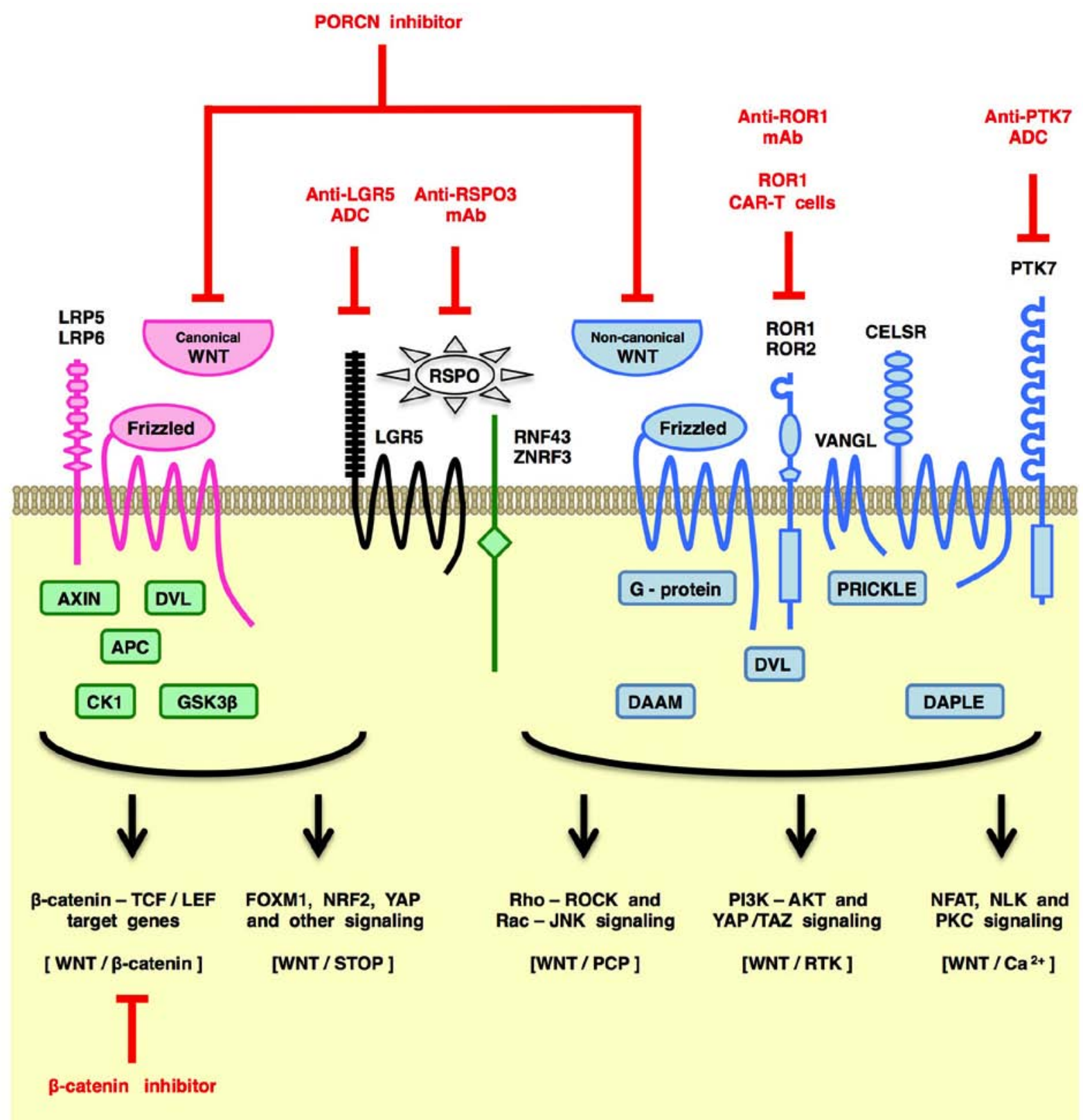

Figure 2. Overview of WNT signaling cascades and WNT signaling-targeted therapeutics. WNT signals are transduced by multiple downstream signaling cascades in a cell context-dependent manner. Canonical WNT signaling through Frizzled (FZD) and LRP5/6 receptors is transduced by the WNT/ $\beta$-catenin and WNT/STOP (stabilization of proteins) signaling cascades, whereas non-canonical WNT signaling through FZD and/or ROR1/ROR2/RYK receptors is transduced by the WNT/PCP (planar cell polarity), WNT/RTK (receptor tyrosine kinase) and WNT/Ca ${ }^{2+}$ signaling cascades. Antibody-based drugs, such as anti-LGR5 antibody-drug conjugate (ADC), anti-RSPO3 monoclonal antibody (mAb), anti-ROR1 mAb and anti-PTK7 ADC, ROR1 chimeric antigen receptormodified T (CAR-T) cells, porcupine (PORCN) inhibitors and $\beta$-catenin inhibitors are representative WNT signaling-targeted therapeutics in clinical trials or preclinical studies for the treatment of cancer patients.

are defective in intrinsic tyrosine kinase activity for autophosphorylation; however, ROR1 and ROR2 can be tyrosine phosphorylated by other tyrosine kinases, such as EGFR, ERBB3, MET and SRC, to activate the PI3K-AKT and YAP signaling cascades (29,74-78) (Fig. 2). WNT/RTK signaling is involved in therapeutic resistance and recurrence of human cancers in part through PI3K-AKT signaling activation.

Non-canonical WNT signals induce cytosolic $\mathrm{Ca}^{2+}$ elevation through $\mathrm{Ca}^{2+}$ release from the endoplasmic reticulum or $\mathrm{Ca}^{2+}$ influx from the extracellular space. WNT signaling through Frizzled receptors are involved in $\mathrm{Ca}^{2+}$ release from the endoplasmic reticulum via small G-protein- or SEC14L2mediated activation of phospholipase $\mathrm{C}$ (PLC) and subsequent generation of inositol-1,4,5-triphosphate $\left(\mathrm{IP}_{3}\right)(21,79-81)$. WNT signaling through Polycystin 1 (PKD1) is proposed to induce $\mathrm{Ca}^{2+}$ influx through a TRPP2 $\mathrm{Ca}^{2+}$ channel (82). $\mathrm{Ca}^{2+} /$ Calmodulin-dependent protein kinase II (CAMK2) and Calcineurin are representative downstream effectors of the $\mathrm{WNT} / \mathrm{Ca}^{2+}$ signaling cascade (Fig. 2). For example, WNT/Ca ${ }^{2+}$ signaling-dependent CAMK2 activation leads to phosphorylation and activation of Nemo-like kinase (NLK), which can inhibit canonical WNT//-catenin signaling in some cells (83). 
WNT-dependent CamK2 activation in cardiomyocytes gives rise to cardiac hypertrophy through phosphorylation and cytoplasmic tethering of Hdac4 and subsequent de-repression of Mef2 target genes (84). WNT/Ca ${ }^{2+}$ signaling-dependent Calcineurin activation leads to dephosphorylation and subsequent nuclear translocation of NFAT for the transcriptional activation of NFAT-target genes (85). By contrast, KRASdependent FZD8 repression in pancreatic cancer cells leads to potentiation of tumorigenesis through $\mathrm{WNT} / \mathrm{Ca}^{2+}$ signaling inhibition (37). WNT/Ca ${ }^{2+}$ signaling to downstream effectors, such as CAMK2 and Calcineurin, is involved in a variety of cellular processes through transcriptional activation of NFAT-target genes, de-repression of MEF2-target genes and repression WNT/ $\beta$-catenin-target genes in a cellular contextdependent manner.

Non-canonical WNT signaling in CSCs is activated by WNT5A, WNT11 and other non-canonical WNT ligands (58) that are secreted from cancer cells $(86,87)$ or stromal/immune cells $(88,89)$, as well as genetic alterations that trans-activate non-canonical WNT signaling cascades, such as E2A-PBXI fusion and MET amplification (74-76). Non-canonical WNT signaling through FZD7 activates the PI3K-AKT signaling cascade as a result of Daple (CCDC88C)-mediated dissociation of G $\beta \gamma$ from Gai (90), whereas non-canonical WNT signaling through ROR1 activates PI3K-AKT signaling cascade owing to ROR1 trans-phosphorylation by other tyrosine kinases, such as MET and SRC (67,75). ROR1 is involved in HER3-Y1307 trans-phosphorylation and subsequent NSUN6-dependent MST1-K59 methylation, which induces YAP/TAZ-dependent transcriptional activation through LATS1/LATS2 inhibition (78). WNT/PCP signaling can also induce Rho-mediated LATS1/LATS2 inhibition for transcriptional activation of YAP/TAZ-target genes $(91,92)$, whereas non-canonical WNT signaling through FZD10 induces YAP/TAZ activation through Ga13 (93). Non-canonical WNT signaling promotes survival and therapeutic resistance of CSCs through PI3K-AKT signaling activation and YAP/TAZ-mediated transcriptional activation.

By contrast, invasion and metastasis are driven by canonical WNT signaling cascades and non-canonical WNT signaling cascades. For example, canonical WNT/ $\beta$-catenin and WNT/ STOP signaling cascades synergistically upregulate SNAI1 to repress epithelial genes, such as $C D H 1$ (E-cadherin), for the initiation of EMT of CSCs, and non-canonical WNT signals promote invasion, survival and metastasis of CSCs or circulating tumor cells $(28,29,35,62,87)$. Together, these findings clearly indicate that canonical $\mathrm{WNT} / \beta$-catenin signaling as well as other WNT signaling cascades are critically involved in the malignant features of CSCs.

\section{Anti-CSC mono-therapy targeting WNT signaling cascades}

WNT signaling cascades are hot and cutting-edge topics in the field of translational oncology and medicinal chemistry (29,94-96). Therapeutics directly targeting WNT signaling cascades are classified into i) ligand/receptor-targeted drugs binding to ligands or transmembrane proteins involved in WNT signaling, ii) porcupine (PORCN) inhibitors abrogating WNT secretion and FZD-dependent signaling, iii) tankyrase (TNKS) inhibitors repressing $\mathrm{WNT} / \beta$-catenin and $\mathrm{WNT}$-independent signaling cascades and iv) $\beta$-catenin inhibitors blocking TCF/LEF-dependent transcription (Table I).

Human/humanized monoclonal antibody (mAb) drugs, such as anti-FZD1/2/5/7/8 mAb (vantictumab/OMP-18R5) (97), anti-FZD5 mAb (IgG-2919) (52), anti-FZD10 antibody-drug conjugate (ADC) (OTSA101-DTPA- ${ }^{90} \mathrm{Y}$ ) (98), anti-LGR5 ADC (mAb-mc-vc-PAB-MMAE) (99), anti-PTK7 ADC (PF-06647020) (100), anti-ROR1 mAb (cirmtuzumab/ UC-961) (101) and anti-RSPO3 mAb (rosmantuzumab/ OMP-131R10) (102) have been developed as large-molecule cancertherapeutics. ROR1CAR-T cells(103)andWNT-trapping FZD8-Fc chimeric protein (ipafricept/OMP-54F28) (104) are also classified as WNT ligand/receptor-targeted drugs. Among this class of therapeutics, cirmtuzumab, ipafricept, PF-06647020, rosmantuzumab and vantictumab, which showed anti-CSC effects in preclinical model experiments, are in clinical trials to treat cancer patients (Table I).

PORCN inhibitors restrain PORCN-dependent palmitoleoylation of WNT family ligands in the endoplasmic reticulum, which obstructs WNT signaling through blockade of WNT secretion as well as palmitoleoylated WNT-mediated oligomerization of FZD receptors (105-108). ETC-159 (109), IWP-2 (110), WNT-C59 (111) and WNT974 (LGK974) (112) are small-molecule PORCN inhibitors. A preclinical study of IWP-2 on organoids derived from colorectal cancer patients revealed that PORNC inhibitors are applicable for the treatment of cancers with RNF43 mutations but not APC mutations (52). By contrast, preclinical studies of WNT974 indicated that PORNC inhibitors repress the survival and tumor initiating potential of CSCs $(43,112)$. ETC-159 and WNT974 are in clinical trials for the treatment of cancer patients (Table I).

TNKS inhibitors repress TNKS-dependent poly-ADPribosylation and subsequent degradation of negative regulators of oncogenic signaling cascades, such as AXIN family proteins, AMOT family proteins, PTEN and TERF1 (TRF1), which results in inhibition of $\mathrm{WNT} / \beta$-catenin signaling, repression of YAP-dependent transcription, suppression of PI3K signaling and telomere shortening, respectively (113-116). AZ1366 (117), G007-LK (118), JW55 (119), NVP-TNKS656 (120) and XAV939 (121) are representative TNKS inhibitors that abrogate WNT/ $\beta$-catenin signaling and tumorigenesis in preclinical mouse model experiments. TNKS inhibitors show synergistic antitumor effects with other therapeutics, such as an AKT inhibitor (API2), EGFR inhibitors (gefitinib and erlotinib), a MEK inhibitor (AZD6244), a PI3K inhibitor (BKM120) and irinotecan $(117,118,120,122-124)$. TNKS inhibitors are promising candidates for CSC-targeted therapeutics; however, because of diverse on-target effects, TNKS inhibitors stalled in their preclinical stage.

$\beta$-catenin inhibitors block TCF/LEF-dependent transcription through inhibition of protein-protein interactions (PPI) between $\beta$-catenin and other transcriptional regulators $(29,125)$, promotion of $\beta$-catenin degradation (126) or inhibition of $\beta$-catenin kinases, such as TNIK (127-129). BC2059 (130), CGP049090 (131), CWP232228(132), ICG-001 (133),LF3 (134), PKF115-584 (135), PRI-724 (136) and SAH-BCL9 (137) are small-molecule $\beta$-catenin PPI inhibitors. MSAB is a smallmolecule compound that binds to $\beta$-catenin and promotes proteasomal degradation of $\beta$-catenin (126). KY-05009 (128), 
Table I. WNT signaling inhibitors and anti-CSC effects.

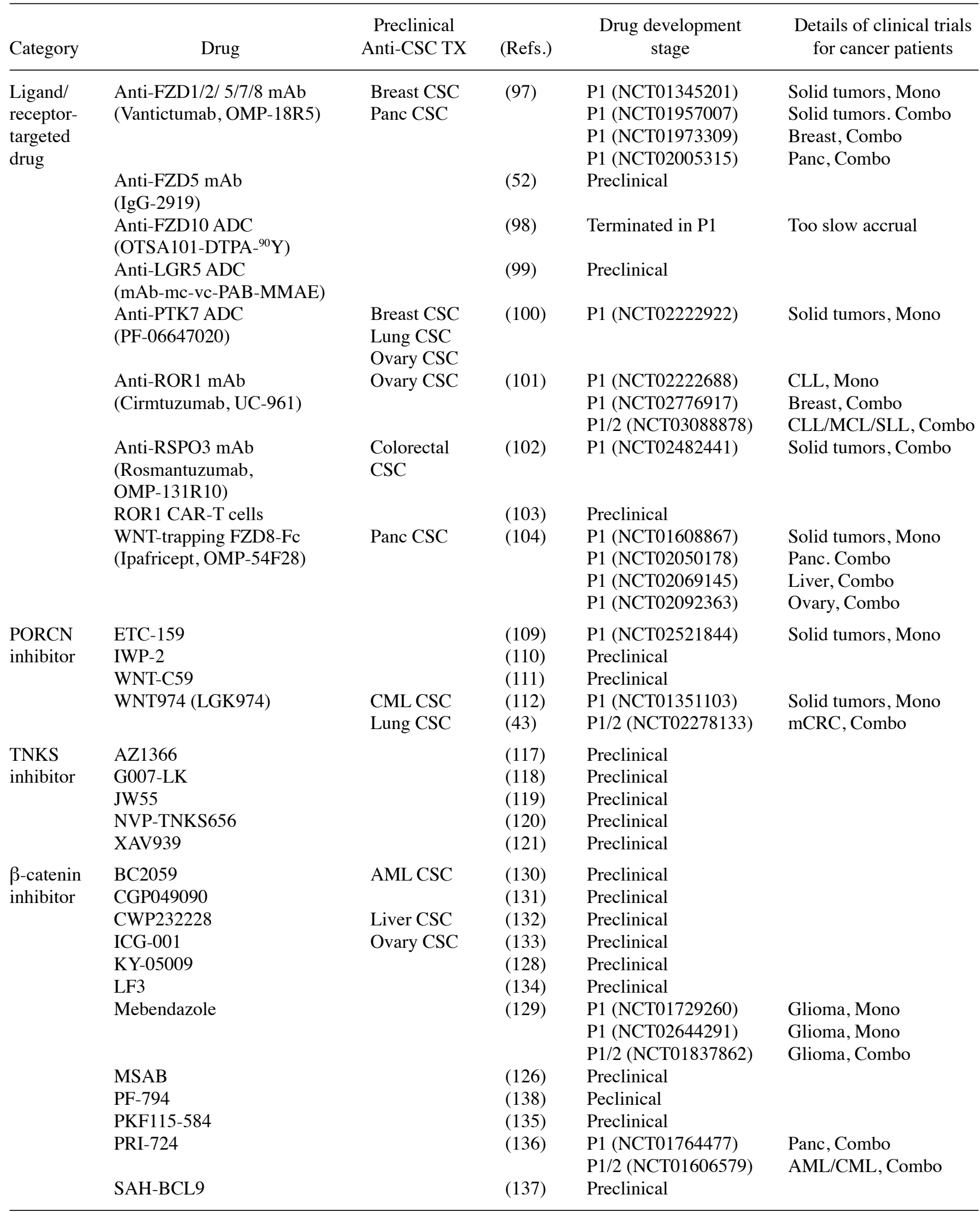

PORCN, porcupine; TNKS, tankyrase; PPI, protein-protein interaction; mAb, monoclonal antibody; bsAb, bispecific antibody; ADC, antibodydrug conjugate; P1, phase I; P2, phase II; AML, acute myeloid leukemia; Breast, breast cancer; CLL, chronic lymphocytic leukemia; CML, chronic myeloid leukemia; Liver, hepatocellular carcinoma; MCL, mantle cell lymphoma; mCRC, metastatic colorectal cancer; NPC, nasopharyngealcarcinoma; NSCLC, non-small cell lung cancer; Ovary, ovarian cancer; Panc, pancreatic cancer; SLL, small lymphocytic lymphoma; Mono, mono-therapy; Combo, combination therapy. 
mebendazole (129) and PF-794 (138) are TNIK inhibitors that repress phosphorylation of TNIK substrates, such as TCF4, FMNL2, PRICKLE1, SMAD1 and SMAD2, which leads to inhibition of $\beta$-catenin-TCF/LEF-dependent transcription and a variety of cellular processes. Among the $\beta$-catenin inhibitors mentioned above, BC2059, CWP232228 and ICG-001 repress the expansion of CSCs. The $\beta$-catenin inhibitors PRI-724 and mebendazole are in phase I/II clinical trials for cancer patients (Table I), whereas other $\beta$-catenin inhibitors are still in the preclinical stage of drug development. $\beta$-catenin inhibitors are challenging therapeutics for cancer patients.

WNT signaling cascades are the major driver of various types of human cancers (29), but the development of many WNT signaling-targeted therapeutics is stuck in the preclinical stage or phase I/II stages of clinical trials (Table I) because of the complexity of WNT signaling cascades and genetic alterations in non-enzymatic signaling components. MAb-based drugs and PORCN inhibitors with the potential to target CSCs as well as bulk cancer cells are promising therapeutics for the patients with WNT signaling-driven cancers.

\section{Anti-CSC combination therapy using WNT signaling- targeted drugs}

Tyrosine kinase inhibitors are rational anticancer therapeutics because tyrosine kinases with intrinsic enzyme activities are aberrantly activated in cancer cells owing to genetic alterations. Tyrosine kinase inhibitors have contributed to the improved prognosis of cancer patients and are essential for genome-based precision medicine; however, unavoidable drug resistance or recurrence is a serious issue for cancer patients and health care systems (4).

Activated tyrosine kinases, such as BCR-ABL fusion kinase, EGFR-T790M mutant, FLT3 internal tandem duplication (FLT3-ITD) mutant, KIT-D814V mutant and RET, promote $\beta$-catenin phosphorylation at Y654 to release $E$-cadherin-bound $\beta$-catenin from the adherens junction for its stabilization and subsequent nuclear translocation (139-143). By contrast, canonical WNT signals inhibit $\beta$-catenin phosphorylation at S33, S37, T41 and S45 to release $\beta$-catenin from proteasomal degradation for its stabilization and nuclear translocation $(21,25,26,29)$. Since canonical WNT signals and oncogenic tyrosine kinases converge to $\beta$-catenin stabilization for the maintenance and expansion of CSCs, canonical WNT signaling inhibitors can block CSC evasion of tyrosine kinase inhibitors. For example, the porcupine inhibitor WNT974 significantly reduced residual stem/progenitor cells of chronic myeloid leukemia (CML) after treatment with the BCR-ABL inhibitor nilotinib via blockade of WNT ligand secretion into the bone marrow microenvironment (112); the $\beta$-catenin inhibitors ICG-001 and PRI-724 induced synergistic effects with the BCR-ABL inhibitors imatinib and nilotinib, respectively, on CML stem/ progenitor cells $(136,144)$; and the TNKS inhibitor AZ1366 and EGFR inhibitor gefitinib showed synergistic effects on lung cancer cells in vivo (124). These preclinical studies indicate that combination therapies using WNT signalingtargeted therapeutics and tyrosine kinase inhibitors might be applicable for treatment of a subset of patients with tyrosine kinase-driven cancers (Fig. 3).
Immune checkpoint blockers that abrogate interactions of ligands and inhibitory receptors on $\mathrm{CD}^{+} \mathrm{T}$ cells are promising antitumor drugs in the clinic or clinical trials (145-151). PD-L1 (CD274) is a representative ligand for inhibitory immune signaling, whereas PD-1 (PDCD1) and CTLA4 are representative receptors for inhibitory immune signaling. Anti-PD-L1 mAbs (atezolizumab, avelumab and durvalumab), anti-PD-1 mAbs (nivolumab and pembrolizumab) and an anti-CTLA4 $\mathrm{mAb}$ (ipilimumab) are approved for the treatment of patients with melanoma or other types of solid tumors. Immune checkpoint blockers result in significant therapeutic effects in a subset of patients; however, the lack of benefits in other patients owing to primary or acquired resistance to immune checkpoint blockers has resulted in a cost-effectiveness issue (152-156).

Canonical WNT signaling activation in melanoma induces immune evasion through CCL4 repression and immunological reprogramming into non-T cell-infiltrated melanoma (11). Since melanoma-derived WNT5A promotes $\beta$-catenin signaling activation and subsequent IDO upregulation in dendritic cells to induce immune evasion through accumulation of regulatory $\mathrm{T}$ (Treg) cells, combination immunotherapy using the porcupine inhibitor WNT-C59 and anti-CTLA4 mAb showed synergistic anti-melanoma effects in vivo (157). By contrast, WNT5A and ROR2 are relatively frequently upregulated in pretreatment tumors of melanoma patients that do not respond to PD-1 immune checkpoint blockade (158), which suggests involvement of non-canonical WNT signaling in resistance to immune checkpoint blockers. Since DKK1-dependent canonical WNT signaling inhibition or putative reciprocal non-canonical WNT signaling activation in tumor microenvironment induces immune evasion through accumulation of myeloid-derived suppressor cells (MDSCs) and depletion of T cells (159), combination therapy using anti-DKK1 mAb (BHQ880 or DKN-01) $(160,161)$ and immune checkpoint blockers might show synergistic antitumor effects in vivo. WNT signaling-targeted therapeutics might be applicable for combination immunotherapy for cancer patients (Fig. 3); however, context-dependent effects of WNT signaling on immunity (4) should be kept in mind.

\section{Omics monitoring for WNT signaling-targeted therapy}

WNT-related human cancers are classified into three major subtypes based on signaling aberrations associated with therapeutic choices (Fig. 3): APC/CTNNB1-altered cancers with $\mathrm{WNT} / \beta$-catenin signaling activation that can be treated with $\beta$-catenin inhibitors; RNF43/ZNRF3/RSPO2/RSPO3-altered cancers with WNT/ $\beta$-catenin and other WNT signaling activation that can be treated with PORCN inhibitors, anti-FZD $\mathrm{mAb}$ or anti-RSPO3 $\mathrm{mAb}$; and ROR1-upregulated cancers with WNT/PCP and WNT/RTK signaling activation that can be treated with anti-ROR1 mAb, anti-ROR1 x CD3 bispecific antibody and ROR1 chimeric antigen receptor-modified $\mathrm{T}$ (CAR-T) cells (29). Genome sequencing, transcriptomic and/or immunohistochemical tests are necessary for the detection and subtyping of WNT signaling-driven cancers and subsequent determination of appropriate WNT signalingtargeted therapeutics (Fig. 3).

WNT signaling-targeted therapeutics are also applicable for combination therapies with tyrosine kinase inhibitors or 

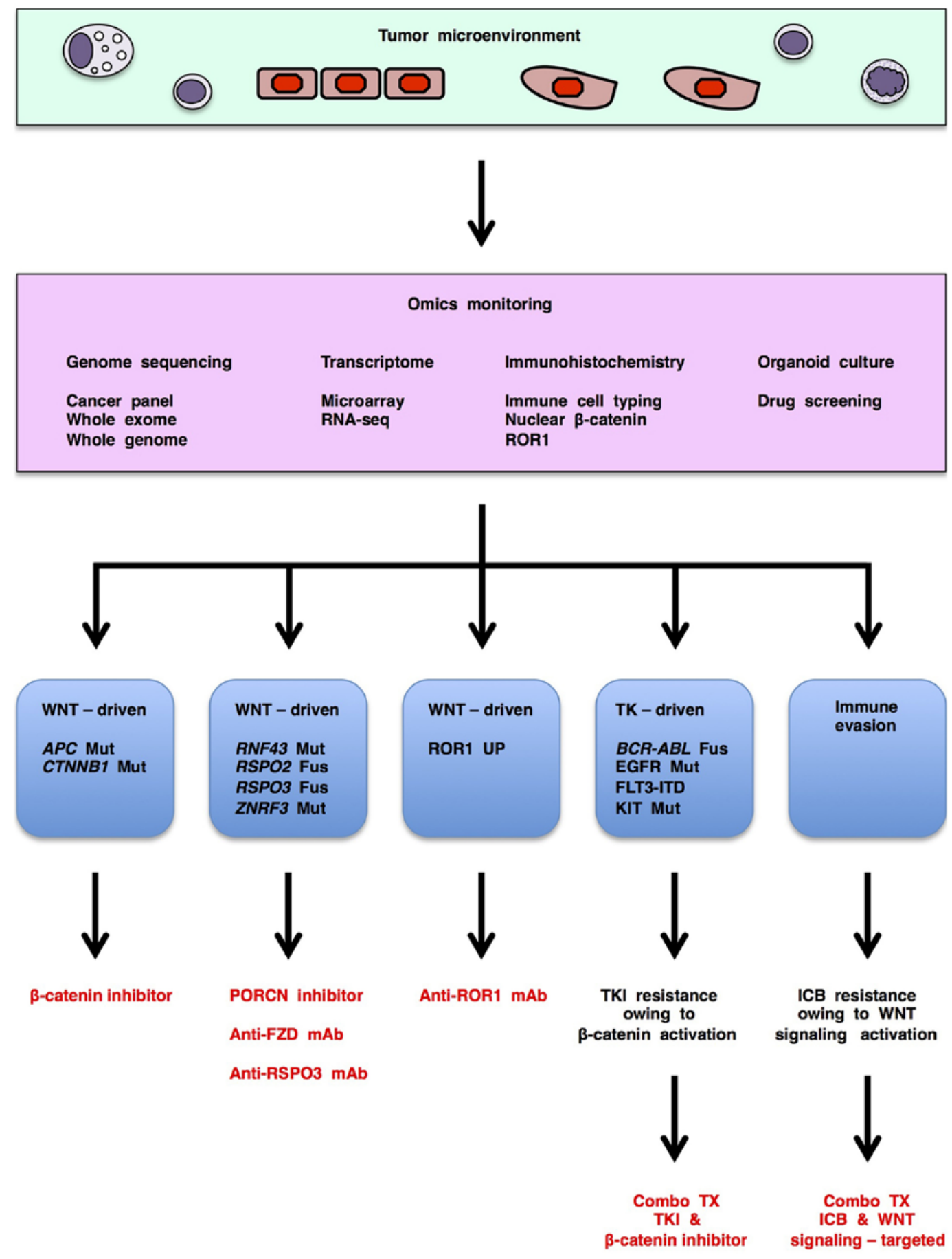

Figure 3. Investigational WNT signaling-targeted therapeutics for genome-based precision medicine. WNT signaling-targeted therapeutics are applicable for mono-therapy of WNT-related human cancers: $\beta$-catenin inhibitors for WNT-driven cancers with APC or CTNNB1 alterations; porcupine (PORCN) inhibitors, anti-FZD or anti-RSPO3 monoclonal antibody $(\mathrm{mAb})$ for WNT-driven cancers with RNF43, RSPO2, RSPO3 or ZNRF3 alterations; and anti-ROR1 mAb for WNT-driven cancers with ROR1 upregulation. By contrast, WNT signaling-targeted therapeutics are applicable for combination therapies with tyrosine kinase inhibitors (TKI) to treat a subset of tyrosine kinase (TK)-driven cancers. WNT signaling-targeted therapeutics are also applicable for combination therapies with immune checkpoint blockers (ICB) to treat cancers with immune evasion; however, because WNT signals regulate immune evasion and antitumor immunity in a context-dependent manner, monitoring of WNT signaling and immunity is mandatory to select an appropriate class of WNT signalingtargeted therapeutics for combination immunotherapy. Therefore, omics monitoring, including genome sequencing, transcriptomic, immunohistochemical and organoid-based tests, is necessary before and during selection of WNT signaling-targeted therapeutics for cancer patients. Mut, mutation; Fus, fusion.

immune checkpoint blockers as mentioned above (Fig. 3). Since resistance to tyrosine kinase inhibitors occur owing to multiple mechanisms, such as acquired drug-resistant mutations in targeted tyrosine kinases, EMT, activation of other tyrosine kinase signaling cascades to bypass targeted tyrosine kinases $(4,162)$ and activation of $\mathrm{WNT} / \beta$-catenin signaling cascade (Fig. 3), genomic, transcriptomic and/or immunohistochemical monitoring during tyrosine kinase inhibitor treatment is also necessary to identify a subset of patients for combination therapy with tyrosine kinase inhibitor and WNT signalingtargeted therapeutics. By contrast, because WNT signaling in the tumor microenvironment orchestrates antitumor immunity 
and immune tolerance in a context-dependent manner, immune monitoring is necessary to choose the appropriate WNT signaling-targeted therapeutics for cancer patients with immune evasion (Fig. 3).

Investigational genome medicine platforms based on nucleotide sequencing of transcribed regions are applicable for determination of targeted therapeutics only in $10-24 \%$ of cancer patients $(163,164)$. Since alterations in non-transcribed regulatory regions also drive human carcinogenesis, wholegenome sequencing rather than whole- or partial-exome sequencing is preferable to improve the precision of genomebased medicine $(4,165)$. In addition, organoid culture is a cutting-edge technology in the fields of oncology and stem cell biology (166-168), and organoid-based tests are also used for selecting targeted therapeutics $(163,166)$. However, because tumor-stromal/immune interactions are not recapitulated in patient-derived organoid models, immunological monitoring in the tumor microenvironment is also necessary to improve genome-based medicine.

Together, these findings indicate that 'omics monitoring', including genome sequencing, transcriptomic, immunohistochemical and organoid-based tests, before and during treatment is necessary to choose and fine-tune WNT signaling-targeted therapeutics for the treatment of cancer patients (Fig. 3).

\section{Conclusion}

Cancer stem cells (CSCs) are part of the tumor microenvironment and survive host defense or therapeutic insult through omics reprogramming. Aberrant WNT signaling activation in human cancers promotes CSC survival, bulk-tumor expansion and invasion/metastasis. Anti-FZD mAb, anti-ROR1 mAb, anti-RSPO3 $\mathrm{mAb}$, PORCN inhibitors and $\beta$-catenin inhibitors are representative WNT signaling-targeted therapeutics in clinical trials or preclinical studies. WNT signaling-targeted therapeutics are applicable for combination therapy with tyrosine kinase inhibitors or immune checkpoint blockers. Omics monitoring is necessary for therapeutic optimization of WNT signaling-targeted therapy.

\section{Acknowledgements}

This study was financially supported in part by a grant-in-aid for the Knowledgebase Project from M. Katoh's Fund.

\section{References}

1. Visvader JE and Lindeman GJ: Cancer stem cells in solid tumours: Accumulating evidence and unresolved questions. Nat Rev Cancer 8: 755-768, 2008.

2. Medema JP: Cancer stem cells: The challenges ahead. Nat Cell Biol 15: 338-344, 2013.

3. Abbaszadegan MR, Bagheri V, Razavi MS, Momtazi AA, Sahebkar A and Gholamin M: Isolation, identification, and characterization of cancer stem cells: A review. J Cell Physiol 232: 2008-2018, 2017

4. Katoh M: Therapeutics targeting FGF signaling network in human diseases. Trends Pharmacol Sci 37: 1081-1096, 2016.

5. de Sousa e Melo F, Kurtova AV, Harnoss JM, Kljavin N, Hoeck JD, Hung J, Anderson JE, Storm EE, Modrusan Z, Koeppen H, et al: A distinct role for Lgr5(+) stem cells in primary and metastatic colon cancer. Nature 543: 676-680, 2017.

6. Koury J, Zhong L and Hao J: Targeting signaling pathways in cancer stem cells for cancer treatment. Stem Cells Int 2017 $2925869,2017$.
7. McDonald OG, Li X, Saunders T, Tryggvadottir R, Mentch SJ, Warmoes MO, Word AE, Carrer A, Salz TH, Natsume S, et al: Epigenomic reprogramming during pancreatic cancer progression links anabolic glucose metabolism to distant metastasis. Nat Genet 49: 367-376, 2017

8. Tam WL and Weinberg RA: The epigenetics of epithelialmesenchymal plasticity in cancer. Nat Med 19: 1438-1449, 2013.

9. Gonzalez DM and Medici D: Signaling mechanisms of the epithelial-mesenchymal transition. Sci Signal 7: re8, 2014.

10. Schreiber RD, Old LJ and Smyth MJ: Cancer immunoediting: Integrating immunity's roles in cancer suppression and promotion. Science 331: 1565-1570, 2011.

11. Spranger S, Bao R and Gajewski TF: Melanoma-intrinsic $\beta$-catenin signalling prevents anti-tumour immunity. Nature 523: 231-235, 2015.

12. Cairns RA, Harris IS and Mak TW: Regulation of cancer cell metabolism. Nat Rev Cancer 11: 85-95, 2011.

13. O'Brien CA, Pollett A, Gallinger S and Dick JE: A human colon cancer cell capable of initiating tumour growth in immunodeficient mice. Nature 445: 106-110, 2007.

14. Yamashita T, Ji J, Budhu A, Forgues M, Yang W, Wang HY, Jia H, Ye Q, Qin LX, Wauthier E, et al: EpCAM-positive hepatocellular carcinoma cells are tumor-initiating cells with stem/progenitor cell features. Gastroenterology 136: 1012-1024, 2009.

15. Todaro M, Gaggianesi M, Catalano V, Benfante A, Iovino F, Biffoni M, Apuzzo T, Sperduti I, Volpe S, Cocorullo G, et al: $\mathrm{CD} 44 \mathrm{v} 6$ is a marker of constitutive and reprogrammed cancer stem cells driving colon cancer metastasis. Cell Stem Cell 14: 342-356, 2014

16. Hirsch D, Barker N, McNeil N, Hu Y, Camps J, McKinnon K, Clevers H, Ried T and Gaiser T: LGR5 positivity defines stem-like cells in colorectal cancer. Carcinogenesis 35: 849-858, 2014.

17. Van der Flier LG, Sabates-Bellver J, Oving I, Haegebarth A, De Palo M, Anti M, Van Gijn ME, Suijkerbuijk S, Van de Wetering M, Marra G, et al: The intestinal Wnt/TCF signature. Gastroenterology 132: 628-632, 2007.

18. Yan KS, Janda CY, Chang J, Zheng GXY, Larkin KA, Luca VC, Chia LA, Mah AT, Han A, Terry JM, et al: Non-equivalence of Wnt and R-spondin ligands during Lgr5(+) intestinal stem-cell self-renewal. Nature 545: 238-242, 2017.

19. Hilkens J, Timmer NC, Boer M, Ikink GJ, Schewe M, Sacchetti A, Koppens MAJ, Song JY and Bakker ERM: RSPO3 expands intestinal stem cell and niche compartments and drives tumorigenesis. Gut 66: 1095-1105, 2017

20. Mani SK, Zhang H, Diab A, Pascuzzi PE, Lefrançois L, Fares N, Bancel B, Merle P and Andrisani O: EpCAM-regulated intramembrane proteolysis induces a cancer stem cell-like gene signature in hepatitis B virus-infected hepatocytes. J Hepatol 65: 888-898, 2016.

21. Katoh M and Katoh M: WNT signaling pathway and stem cell signaling network. Clin Cancer Res 13: 4042-4045, 2007.

22. Ranganathan P, Weaver KL and Capobianco AJ: Notch signalling in solid tumours: A little bit of everything but not all the time. Nat Rev Cancer 11: 338-351, 2011.

23. Katoh $\mathrm{M}$ and Nakagama H: FGF receptors: Cancer biology and therapeutics. Med Res Rev 34: 280-300, 2014.

24. Lamb R, Bonuccelli G, Ozsvári B, Peiris-Pagès M, Fiorillo M, Smith DL, Bevilacqua G, Mazzanti CM, McDonnell LA, Naccarato AG, et al: Mitochondrial mass, a new metabolic biomarker for stem-like cancer cells: Understanding WNT/ FGF-driven anabolic signaling. Oncotarget 6: 30453-30471, 2015.

25. Niehrs C: The complex world of WNT receptor signalling. Nat Rev Mol Cell Biol 13: 767-779, 2012.

26. Holland JD, Klaus A, Garratt AN and Birchmeier W: Wnt signaling in stem and cancer stem cells. Curr Opin Cell Biol 25: 254-264, 2013.

27. Rada P, Rojo AI, Offergeld A, Feng GJ, Velasco-Martín JP, González-Sancho JM, Valverde ÁM, Dale T, Regadera J and Cuadrado A: WNT-3A regulates an Axin1/NRF2 complex that regulates antioxidant metabolism in hepatocytes. Antioxid Redox Signal 22: 555-571, 2015.

28. Acebron SP and Niehrs C: $\beta$-catenin-independent roles of Wnt/LRP6 signaling. Trends Cell Biol 26: 956-967, 2016.

29. Katoh M and Katoh M: Molecular genetics and targeted therapy of WNT-related human diseases (Review). Int J Mol Med 40: 587-606, 2017.

30. Lui JH, Hansen DV and Kriegstein AR: Development and evolution of the human neocortex. Cell 146: 18-36, 2011. 
31. Barker N: Adult intestinal stem cells: Critical drivers of epithelial homeostasis and regeneration. Nat Rev Mol Cell Biol 15: 19-33, 2014.

32. Van Camp JK, Beckers S, Zegers D and Van Hul W: Wnt signaling and the control of human stem cell fate. Stem Cell Rev 10: 207-229, 2014.

33. Yang K, Wang X, Zhang H, Wang Z, Nan G, Li Y, Zhang F, Mohammed MK, Haydon RC, Luu HH, et al: The evolving roles of canonical WNT signaling in stem cells and tumorigenesis: Implications in targeted cancer therapies. Lab Invest 96: 116-136, 2016.

34. Qin L, Yin YT, Zheng FJ, Peng LX, Yang CF, Bao YN, Liang YY, Li XJ, Xiang YQ, Sun R, et al: WNT5A promotes stemness characteristics in nasopharyngeal carcinoma cells leading to metastasis and tumorigenesis. Oncotarget 6: 10239-10252, 2015.

35. Webster MR, Kugel CH III and Weeraratna AT: The Wnts of change: How Wnts regulate phenotype switching in melanoma. Biochim Biophys Acta 1856: 244-251, 2015.

36. Kumawat K and Gosens R: WNT-5A: Signaling and functions in health and disease. Cell Mol Life Sci 73: 567-587, 2016.

37. Wang MT, Holderfield M, Galeas J, Delrosario R, To MD, Balmain A and McCormick F: K-Ras promotes tumorigenicity through suppression of non-canonical Wnt signaling. Cell 163 : 1237-1251, 2015.

38. Plaks V, Kong N and Werb Z: The cancer stem cell niche: How essential is the niche in regulating stemness of tumor cells? Cell Stem Cell 16: 225-238, 2015.

39. Katoh M: FGFR inhibitors: Effects on cancer cells, tumor microenvironment and whole-body homeostasis (Review). Int J Mol Med 38: 3-15, 2016.

40. Bolli N, Avet-Loiseau H, Wedge DC, Van Loo P, Alexandrov LB, Martincorena I, Dawson KJ, Iorio F, Nik-Zainal S, Bignell GR, et al: Heterogeneity of genomic evolution and mutational profiles in multiple myeloma. Nat Commun 5: 2997, 2014.

41. Li S, Garrett-Bakelman FE, Chung SS, Sanders MA, Hricik T, Rapaport F, Patel J, Dillon R, Vijay P, Brown AL, et al: Distinct evolution and dynamics of epigenetic and genetic heterogeneity in acute myeloid leukemia. Nat Med 22: 792-799, 2016.

42. Abbosh C, Birkbak NJ, Wilson GA, Jamal-Hanjani M, Constantin T, Salari R, Le Quesne J, Moore DA, Veeriah S, Rosenthal R, et al; TRACERx consortium; PEACE consortium: Phylogenetic ctDNA analysis depicts early-stage lung cancer evolution. Nature 545: 446-451, 2017.

43. Tammela T, Sanchez-Rivera FJ, Cetinbas NM, Wu K, Joshi NS, Helenius K, Park Y, Azimi R, Kerper NR, Wesselhoeft RA et al: A Wnt-producing niche drives proliferative potential and progression in lung adenocarcinoma. Nature 545: 355-359, 2017.

44. Weis SM and Cheresh DA: Tumor angiogenesis: Molecular pathways and therapeutic targets. Nat Med 17: 1359-1370, 2011.

45. Mao Y, Keller ET, Garfield DH, Shen K and Wang J: Stromal cells in tumor microenvironment and breast cancer. Cancer Metastasis Rev 32: 303-315, 2013.

46. Son B, Lee S, Youn H, Kim E, Kim W and Youn B: The role of tumor microenvironment in therapeutic resistance. Oncotarget 8: 3933-3945, 2017

47. Anderson KG, Stromnes IM and Greenberg PD: Obstacles posed by the tumor microenvironment to $T$ cell activity: A case for synergistic therapies. Cancer Cell 31: 311-325, 2017.

48. Wang Z, Liu P, Inuzuka H and Wei W: Roles of F-box proteins in cancer. Nat Rev Cancer 14: 233-247, 2014.

49. Katoh M, Hirai M, Sugimura T and Terada M: Cloning, expression and chromosomal localization of Wnt-13, a novel member of the Wnt gene family. Oncogene 13: 873-876, 1996.

50. Katoh M, Kirikoshi H, Terasaki $\mathrm{H}$ and Shiokawa K: WNT2B2 mRNA, up-regulated in primary gastric cancer, is a positive regulator of the WNT- $\beta$-catenin-TCF signaling pathway. Biochem Biophys Res Commun 289: 1093-1098, 2001.

51. Jiang H, Li F, He C, Wang X, Li Q and Gao H: Expression of Gli1 and Wnt2B correlates with progression and clinical outcome of pancreatic cancer. Int J Clin Exp Pathol 7: 4531-4538, 2014.

52. Steinhart Z, Pavlovic Z, Chandrashekhar M, Hart T, Wang X, Zhang X, Robitaille M, Brown KR, Jaksani S, Overmeer R, et al: Genome-wide CRISPR screens reveal a Wnt-FZD5 signaling circuit as a druggable vulnerability of $R N F 43$-mutant pancreatic tumors. Nat Med 23: 60-68, 2017.

53. Seshagiri S, Stawiski EW, Durinck S, Modrusan Z, Storm EE, Conboy CB, Chaudhuri S, Guan Y, Janakiraman V, Jaiswal BS et al: Recurrent R-spondin fusions in colon cancer. Nature 488: 660-664, 2012

54. Kinzler KW and Vogelstein B: Lessons from hereditary colorectal cancer. Cell 87: 159-170, 1996.
55. Mazzoni SM and Fearon ER: $A X I N 1$ and $A X I N 2$ variants in gastrointestinal cancers. Cancer Lett 355: 1-8, 2014.

56. Chiche A, Moumen M, Romagnoli M, Petit V, Lasla H, Jézéquel P, de la Grange P, Jonkers J, Deugnier MA, Glukhova MA, et al: p53 deficiency induces cancer stem cell pool expansion in a mouse model of triple-negative breast tumors. Oncogene 36: 2355-2365, 2017

57. Valenti G, Quinn HM, Heynen GJJE, Lan L, Holland JD, Vogel R, Wulf-Goldenberg A and Birchmeier W: Cancer stem cells regulate cancer-associated fibroblasts via activation of Hedgehog signaling in mammary gland tumors. Cancer Res 77: 2134-2147, 2017.

58. Katoh M: WNT/PCP signaling pathway and human cancer (Review). Oncol Rep 14: 1583-1588, 2005.

59. Yang Y and Mlodzik M: Wnt-Frizzled/planar cell polarity signaling: Cellular orientation by facing the wind (Wnt). Annu Rev Cell Dev Biol 31: 623-646, 2015.

60. Minegishi K, Hashimoto M, Ajima R, Takaoka K, Shinohara K, Ikawa Y, Nishimura H, McMahon AP, Willert K, Okada Y, et al: A Wnt5 activity asymmetry and intercellular signaling via PCP proteins polarize node cells for left-right symmetry breaking. Dev Cell 40: 439-452.e4, 2017.

61. Wu J and Mlodzik M: Wnt/PCP instructions for cilia in left-right asymmetry. Dev Cell 40: 423-424, 2017.

62. Wang W, Runkle KB, Terkowski SM, Ekaireb RI and Witze ES: Protein depalmitoylation is induced by Wnt5a and promotes polarized cell behavior. J Biol Chem 290: 15707-15716, 2015.

63. Nishimura T, Honda $\mathrm{H}$ and Takeichi M: Planar cell polarity links axes of spatial dynamics in neural-tube closure. Cell 149: 1084-1097, 2012

64. De Marco P, Merello E, Piatelli G, Cama A, Kibar Z and Capra V: Planar cell polarity gene mutations contribute to the etiology of human neural tube defects in our population. Birth Defects Res A Clin Mol Teratol 100: 633-641, 2014.

65. Gödde NJ, Pearson HB, Smith LK and Humbert PO: Dissecting the role of polarity regulators in cancer through the use of mouse models. Exp Cell Res 328: 249-257, 2014.

66. Johnson R and Halder G: The two faces of Hippo: Targeting the Hippo pathway for regenerative medicine and cancer treatment. Nat Rev Drug Discov 13: 63-79, 2014.

67. Zhang S, Chen L, Cui B, Chuang HY, Yu J, Wang-Rodriguez J, Tang L, Chen G, Basak GW and Kipps TJ: ROR1 is expressed in human breast cancer and associated with enhanced tumor-cell growth. PLoS One 7: e31127, 2012.

68. Anastas JN, Kulikauskas RM, Tamir T, Rizos H, Long GV, von Euw EM, Yang PT, Chen HW, Haydu L, Toroni RA, et al: WNT5A enhances resistance of melanoma cells to targeted BRAF inhibitors. J Clin Invest 124: 2877-2890, 2014.

69. Yu J, Chen L, Cui B, Widhopf GF II, Shen Z, Wu R, Zhang L, Zhang S, Briggs SP and Kipps TJ: Wnt5a induces ROR1/ROR2 heterooligomerization to enhance leukemia chemotaxis and proliferation. J Clin Invest 126: 585-598, 2016.

70. Green JL, Kuntz SG and Sternberg PW: Ror receptor tyrosine kinases: Orphans no more. Trends Cell Biol 18: 536-544, 2008.

71. Lu W, Yamamoto V, Ortega B and Baltimore D: Mammalian Ryk is a Wnt coreceptor required for stimulation of neurite outgrowth. Cell 119: 97-108, 2004.

72. Petrova IM, Malessy MJ, Verhaagen J, Fradkin LG and Noordermeer JN: Wnt signaling through the Ror receptor in the nervous system. Mol Neurobiol 49: 303-315, 2014.

73. Debebe $Z$ and Rathmell WK: Ror2 as a therapeutic target in cancer. Pharmacol Ther 150: 143-148, 2015.

74. Bicocca VT, Chang BH, Masouleh BK, Muschen M,Loriaux MM, Druker BJ and Tyner JW: Crosstalk between ROR1 and the Pre-B cell receptor promotes survival of $t(1 ; 19)$ acute lymphoblastic leukemia. Cancer Cell 22: 656-667, 2012.

75. Hojjat-Farsangi M, Moshfegh A, Daneshmanesh AH, Khan AS, Mikaelsson E, Osterborg A and Mellstedt H: The receptor tyrosine kinase ROR1 - an oncofetal antigen for targeted cancer therapy. Semin Cancer Biol 29: 21-31, 2014.

76. Gentile A,Lazzari L, Benvenuti S, Trusolino L and Comoglio PM: The ROR1 pseudokinase diversifies signaling outputs in MET-addicted cancer cells. Int J Cancer 135: 2305-2316, 2014.

77. Yamaguchi T, Lu C, Ida L, Yanagisawa K, Usukura J, Cheng J, Hotta N, Shimada Y, Isomura H, Suzuki M, et al: ROR1 sustains caveolae and survival signalling as a scaffold of cavin-1 and caveolin-1. Nat Commun 7: 10060, 2016.

78. Li C, Wang S, Xing Z, Lin A, Liang K, Song J, Hu Q, Yao J, Chen Z, Park PK, et al: A ROR1-HER3-lncRNA signalling axis modulates the Hippo-YAP pathway to regulate bone metastasis. Nat Cell Biol 19: 106-119, 2017. 
79. Dijksterhuis JP, Petersen J and Schulte G: WNT/Frizzled signalling: receptor-ligand selectivity with focus on FZD-G protein signalling and its physiological relevance: IUPHAR Review 3. Br J Pharmacol 171: 1195-1209, 2014

80. Zhan T, Rindtorff N and Boutros M: Wnt signaling in cancer. Oncogene 36: 1461-1473, 2017.

81. Gong B, Shen W, Xiao W, Meng Y, Meng A and Jia S: The Sec14-like phosphatidylinositol transfer proteins Sec1413/ SEC14L2 act as GTPase proteins to mediate $\mathrm{Wnt} / \mathrm{Ca}(2+)$ signaling. eLife 6: e26362, 2017.

82. Kim S, Nie H, Nesin V, Tran U, Outeda P, Bai CX, Keeling J, Maskey D, Watnick T, Wessely O, et al: The polycystin complex mediates Wnt/Ca(2+) signalling. Nat Cell Biol 18: 752-764, 2016.

83. Ishitani T, Kishida S, Hyodo-Miura J, Ueno N, Yasuda J, Waterman M, Shibuya H, Moon RT, Ninomiya-Tsuji J and Matsumoto K: The TAK1-NLK mitogen-activated protein kinase cascade functions in the Wnt-5a/Ca(2+) pathway to antagonize Wnt/ $\beta$-catenin signaling. Mol Cell Biol 23: 131-139, 2003

84. Zhang M, Hagenmueller M, Riffel JH, Kreusser MM, Bernhold E, Fan J, Katus HA, Backs J and Hardt SE: Calcium/calmodulindependent protein kinase II couples Wnt signaling with histone deacetylase 4 and mediates dishevelled-induced cardiomyopathy. Hypertension 65: 335-344, 2015.

85. Scholz B, Korn C, Wojtarowicz J, Mogler C, Augustin I, Boutros M, Niehrs C and Augustin HG: Endothelial RSPO3 controls vascular stability and pruning through non-canonical WNT/Ca(2+)/NFAT signaling. Dev Cell 36: 79-93, 2016.

86. Wang W, Snyder N, Worth AJ, Blair IA and Witze ES: Regulation of lipid synthesis by the RNA helicase Mov10 controls Wnt5a production. Oncogenesis 4: e154, 2015.

87. Miyamoto DT, Zheng Y, Wittner BS, Lee RJ,Zhu H,Broderick KT Desai R, Fox DB, Brannigan BW, Trautwein J, et al: RNA-Seq of single prostate CTCs implicates noncanonical Wnt signaling in antiandrogen resistance. Science 349: 1351-1356, 2015.

88. Blumenthal A, Ehlers S, Lauber J, Buer J, Lange C, Goldmann T, Heine $\mathrm{H}$, Brandt $\mathrm{E}$ and Reiling $\mathrm{N}$ : The Wingless homolog WNT5A and its receptor Frizzled-5 regulate inflammatory responses of human mononuclear cells induced by microbial stimulation. Blood 108: 965-973, 2006.

89. Wang L, Steele I, Kumar JD, Dimaline R, Jithesh PV, Tiszlavicz L, Reisz Z, Dockray GJ and Varro A: Distinct miRNA profiles in normal and gastric cancer myofibroblasts and significance in Wnt signaling. Am J Physiol Gastrointest Liver Physiol 310: G696-G704, 2016

90. Aznar N, Midde KK, Dunkel Y, Lopez-Sanchez I, Pavlova Y, Marivin A, Barbazán J, Murray F, Nitsche U, Janssen KP, et al: Daple is a novel non-receptor GEF required for trimeric $\mathrm{G}$ protein activation in Wnt signaling. eLife 4: e07091, 2015.

91. Yu FX, Zhao B and Guan KL: Hippo pathway in organ size control, tissue homeostasis, and cancer. Cell 163: 811-828, 2015.

92. Hansen CG, Moroishi T and Guan KL: YAP and TAZ: A nexus for Hippo signaling and beyond. Trends Cell Biol 25: 499-513, 2015.

93. Hot B, Valnohova J, Arthofer E, Simon K, Shin J, Uhlén M, Kostenis E, Mulder J and Schulte G: FZD10-G $\alpha 13$ signalling axis points to a role of FZD10 in CNS angiogenesis. Cell Signal 32: 93-103, 2017

94. Takebe N, Miele L, Harris PJ, Jeong W, Bando H, Kahn M, Yang SX and Ivy SP: Targeting Notch, Hedgehog, and Wnt pathways in cancer stem cells: Clinical update. Nat Rev Clin Oncol 12: 445-464, 2015

95. Kahn M: Wnt signaling in stem cells and tumor stem cells. Semin Reprod Med 33: 317-325, 2015.

96. Tai D, Wells K, Arcaroli J, Vanderbilt C, Aisner DL, Messersmith WA and Lieu CH: Targeting the WNT signaling pathway in cancer therapeutics. Oncologist 20: 1189-1198, 2015.

97. Gurney A, Axelrod F, Bond CJ, Cain J, Chartier C, Donigan L, Fischer M, Chaudhari A, Ji M, Kapoun AM, et al: Wnt pathway inhibition via the targeting of Frizzled receptors results in decreased growth and tumorigenicity of human tumors. Proc Natl Acad Sci USA 109: 11717-11722, 2012.

98. Nielsen TO, Poulin NM and Ladanyi M: Synovial sarcoma: Recent discoveries as a roadmap to new avenues for therapy. Cancer Discov 5: 124-134, 2015.

99. Gong X, Azhdarinia A, Ghosh SC, Xiong W, An Z, Liu Q and Carmon KS: LGR5-targeted antibody-drug conjugate eradicates gastrointestinal tumors and prevents recurrence. Mol Cancer Ther 15: 1580-1590, 2016.
100. Damelin M, Bankovich A, Bernstein J, Lucas J, Chen L, Williams S, Park A, Aguilar J, Ernstoff E, Charati M, et al: A PTK7-targeted antibody-drug conjugate reduces tumorinitiating cells and induces sustained tumor regressions. Sci Transl Med 9, pii: eaag2611, 2017.

101.Zhang S, Cui B, Lai H, Liu G, Ghia EM, Widhopf GF II, Zhang Z, Wu CC, Chen L, Wu R, et al: Ovarian cancer stem cells express ROR1, which can be targeted for anti-cancerstem-cell therapy. Proc Natl Acad Sci USA 111: 17266-17271, 2014.

102. Storm EE, Durinck S, de Sousa e Melo F, Tremayne J, Kljavin N, Tan C, Ye X, Chiu C, Pham T, Hongo JA, et al: Targeting PTPRK-RSPO3 colon tumours promotes differentiation and loss of stem-cell function. Nature 529: 97-100, 2016.

103. Berger C, Sommermeyer D, Hudecek M, Berger M, Balakrishnan A, Paszkiewicz PJ, Kosasih PL, Rader C and Riddell SR: Safety of targeting ROR1 in primates with chimeric antigen receptor-modified T cells. Cancer Immunol Res 3: 206-216, 2015

104. Le PN, McDermott JD and Jimeno A: Targeting the Wnt pathway in human cancers: Therapeutic targeting with a focus on OMP-54F28. Pharmacol Ther 146: 1-11, 2015.

105. Cheng Y, Phoon YP, Jin X, Chong SY, Ip JC, Wong BW and Lung ML: Wnt-C59 arrests stemness and suppresses growth of nasopharyngeal carcinoma in mice by inhibiting the Wnt pathway in the tumor microenvironment. Oncotarget 6: 14428-14439, 2015.

106. Poulsen A, Ho SY, Wang W, Alam J, Jeyaraj DA, Ang SH, Tan ES, Lin GR, Cheong VW, Ke Z, et al: Pharmacophore model for Wnt/Porcupine inhibitors and its use in drug design. $\mathrm{J}$ Chem Inf Model 55: 1435-1448, 2015.

107. Langton PF, Kakugawa S and Vincent JP: Making, exporting, and modulating Wnts. Trends Cell Biol 26: 756-765, 2016.

108. DeBruine ZJ, Ke J, Harikumar KG, Gu X, Borowsky P, Williams BO, Xu W, Miller LJ, Xu HE and Melcher K: Wnt5a promotes Frizzled-4 signalosome assembly by stabilizing cysteine-rich domain dimerization. Genes Dev 31: 916-926, 2017.

109. Madan B, Ke Z, Harmston N, Ho SY, Frois AO, Alam J, Jeyaraj DA, Pendharkar V, Ghosh K, Virshup IH, et al: Wnt addiction of genetically defined cancers reversed by PORCN inhibition. Oncogene 35: 2197-2207, 2016.

110. Chen B, Dodge ME, Tang W, Lu J, Ma Z, Fan CW, Wei S, Hao W, Kilgore J, Williams NS, et al: Small molecule-mediated disruption of Wnt-dependent signaling in tissue regeneration and cancer. Nat Chem Biol 5: 100-107, 2009.

111. Proffitt KD, Madan B, Ke Z, Pendharkar V, Ding L, Lee MA, Hannoush RN and Virshup DM: Pharmacological inhibition of the Wnt acyltransferase PORCN prevents growth of WNT-driven mammary cancer. Cancer Res 73: 502-507, 2013.

112. Agarwal P, Zhang B, Ho Y, Cook A, Li L, Mikhail FM, Wang Y, McLaughlin ME and Bhatia R: Enhanced targeting of CML stem and progenitor cells by inhibition of porcupine acyltransferase in combination with TKI. Blood 129: 1008-1020, 2017.

113. Liu C and Yu X: ADP-ribosyltransferases and poly ADP-ribosylation. Curr Protein Pept Sci 16: 491-501, 2015.

114. Kulak O, Chen H, Holohan B, Wu X, He H, Borek D, Otwinowski Z, Yamaguchi K, Garofalo LA, Ma Z, et al: Disruption of Wnt/ $\beta$-catenin signaling and telomeric shortening are inextricable consequences of tankyrase inhibition in human cells. Mol Cell Biol 35: 2425-2435, 2015.

115. Wang W, Li N, Li X, Tran MK, Han X and Chen J: Tankyrase inhibitors target YAP by stabilizing Angiomotin family proteins. Cell Rep 13: 524-532, 2015.

116. Nathubhai A, Haikarainen T, Koivunen J, Murthy S Koumanov F, Lloyd MD, Holman GD, Pihlajaniemi T, Tosh D, Lehtiö L, et al: Highly potent and isoform selective dual site binding Tankyrase/Wnt signaling inhibitors that increase cellular glucose uptake and have antiproliferative activity. J Med Chem 60: 814-820, 2017.

117. Quackenbush KS, Bagby S, Tai WM, Messersmith WA, Schreiber A, Greene J, Kim J, Wang G, Purkey A, Pitts TM, et al: The novel tankyrase inhibitor (AZ1366) enhances irinotecan activity in tumors that exhibit elevated tankyrase and irinotecan resistance. Oncotarget 7: 28273-28285, 2016 .

118. Lau T, Chan E, Callow M, Waaler J, Boggs J, Blake RA, Magnuson S, Sambrone A, Schutten M, Firestein R, et al: A novel tankyrase small-molecule inhibitor suppresses APC mutation-driven colorectal tumor growth. Cancer Res 73: 3132-3144, 2013 
119. Waaler J, Machon O, Tumova L, Dinh H, Korinek V, Wilson SR, Paulsen JE, Pedersen NM, Eide TJ, Machonova O, et al: A novel tankyrase inhibitor decreases canonical Wnt signaling in colon carcinoma cells and reduces tumor growth in conditional APC mutant mice. Cancer Res 72: 2822-2832, 2012.

120. Arqués O, Chicote I, Puig I, Tenbaum SP, Argilés G, Dienstmann R, Fernández N, Caratù G, Matito J, Silberschmidt D, et al: Tankyrase inhibition blocks $\mathrm{Wnt} / \beta$-catenin pathway and reverts resistance to $\mathrm{PI} 3 \mathrm{~K}$ and $\mathrm{AKT}$ inhibitors in the treatment of colorectal cancer. Clin Cancer Res 22: 644-656, 2016.

121. Huang SM, Mishina YM, Liu S, Cheung A, Stegmeier F, Michaud GA, Charlat O, Wiellette E, Zhang Y, Wiessner S, et al: Tankyrase inhibition stabilizes axin and antagonizes Wnt signalling. Nature 461: 614-620, 2009.

122. Schoumacher M, Hurov KE, Lehár J, Yan-Neale Y, Mishina Y, Sonkin D, Korn JM, Flemming D, Jones MD, Antonakos B, et al: Inhibiting Tankyrases sensitizes KRAS-mutant cancer cells to MEK inhibitors via FGFR2 feedback signaling. Cancer Res 74: 3294-3305, 2014

123. Wang H, Lu B, Castillo J, Zhang Y, Yang Z, McAllister G, Lindeman A, Reece-Hoyes J, Tallarico J, Russ C, et al: Tankyrase inhibitor sensitizes lung cancer cells to endothelial growth factor receptor (EGFR) inhibition via stabilizing angiomotins and inhibiting YAP signaling. J Biol Chem 291: 15256-15266, 2016.

124. Scarborough HA, Helfrich BA, Casás-Selves M, Schuller AG, Grosskurth SE, Kim J, Tan AC, Chan DC, Zhang Z, Zaberezhnyy V, et al: AZ1366: An inhibitor of tankyrase and the canonical Wnt pathway that limits the persistence of non-small cell lung cancer cells following EGFR inhibition. Clin Cancer Res 23: 1531-1541, 2017.

125.Pelay-Gimeno M, Glas A, Koch O and Grossmann TN Structure-based design of inhibitors of protein-protein interactions: Mimicking peptide binding epitopes. Angew Chem Int Ed Engl 54: 8896-8927, 2015.

126. Hwang SY, Deng X, Byun S, Lee C, Lee SJ, Suh H, Zhang J, Kang Q, Zhang T, Westover KD, et al: Direct targeting of $\beta$-catenin by a small molecule stimulates proteasomal degradation and suppresses oncogenic Wnt/ $\beta$-catenin signaling. Cell Rep 16: 28-36, 2016.

127. Mahmoudi T, Li VS, Ng SS, Taouatas N, Vries RG, Mohammed S, Heck AJ and Clevers H: The kinase TNIK is an essential activator of Wnt target genes. EMBO J 28: 3329-3340, 2009.

128. Lee Y, Jung JI, Park KY, Kim SA and Kim J: Synergistic inhibition effect of TNIK inhibitor KY-05009 and receptor tyrosine kinase inhibitor dovitinib on IL-6-induced proliferation and Wnt signaling pathway in human multiple myeloma cells. Oncotarget 8: 41091-41101, 2017

129.Tan Z, Chen L and Zhang S: Comprehensive modeling and discovery of mebendazole as a novel TRAF2- and NCK-interacting kinase inhibitor. Sci Rep 6: 33534, 2016.

130. Fiskus W, Sharma S, Saha S, Shah B, Devaraj SG, Sun B, Horrigan S, Leveque C, Zu Y, Iyer S, et al: Pre-clinical efficacy of combined therapy with novel $\beta$-catenin antagonist BC2059 and histone deacetylase inhibitor against AML cells. Leukemia 29: 1267-1278, 2015.

131. Trautmann M, Sievers E, Aretz S, Kindler D, Michels S, Friedrichs N, Renner M, Kirfel J, Steiner S, Huss S, et al: SS18-SSX fusion protein-induced Wnt/ $\beta$-catenin signaling is a therapeutic target in synovial sarcoma. Oncogene 33: 5006-5016, 2014.

132.Kim JY, Lee HY, Park KK, Choi YK, Nam JS and Hong IS: CWP232228 targets liver cancer stem cells through Wnt/ $\beta$-catenin signaling: A novel therapeutic approach for liver cancer treatment. Oncotarget 7: 20395-20409, 2016.

133. Nagaraj AB, Joseph P, Kovalenko O, Singh S, Armstrong A, Redline R, Resnick K, Zanotti K, Waggoner S and DiFeo A: Critical role of $\mathrm{Wnt} / \beta$-catenin signaling in driving epithelial ovarian cancer platinum resistance. Oncotarget 6: 23720-23734, 2015.

134.Fang L, Zhu Q, Neuenschwander M, Specker E, WulfGoldenberg A, Weis WI, von Kries JP and Birchmeier W: A small-molecule antagonist of the $\beta$-catenin/TCF4 interaction blocks the self-renewal of cancer stem cells and suppresses tumorigenesis. Cancer Res 76: 891-901, 2016.

135. Sukhdeo K, Mani M, Zhang Y, Dutta J, Yasui H, Rooney MD, Carrasco DE, Zheng M, He H, Tai YT, et al: Targeting the $\beta$-catenin/TCF transcriptional complex in the treatment of multiple myeloma. Proc Natl Acad Sci USA 104: 7516-7521, 2007.
136.Zhou H, Mak PY, Mu H, Mak DH, Zeng Z, Cortes J, Liu Q, Andreeff $M$ and Carter BZ: Combined inhibition of $\beta$-catenin and Bcr-Abl synergistically targets tyrosine kinase inhibitorresistant blast crisis chronic myeloid leukemia blasts and progenitors in vitro and in vivo. Leukemia: Apr 18, 2017 (Epub ahead of print) doi: 10.1038/leu.2017.87.

137. Takada K, Zhu D, Bird GH, Sukhdeo K, Zhao JJ, Mani M, Lemieux M, Carrasco DE, Ryan J, Horst D, et al: Targeted disruption of the BCL9/ $\beta$-catenin complex inhibits oncogenic Wnt signaling. Sci Transl Med 4: 148ra117, 2012.

138. Wang Q, Amato SP, Rubitski DM, Hayward MM, Kormos BL, Verhoest PR, Xu L, Brandon NJ and Ehlers MD: Identification of phosphorylation consensus sequences and endogenous neuronal substrates of the psychiatric risk kinase TNIK. J Pharmacol Exp Ther 356: 410-423, 2016.

139. Coluccia AM, Vacca A, Duñach M, Mologni L, Redaelli S, Bustos VH, Benati D, Pinna LA and Gambacorti-Passerini C: Bcr-Abl stabilizes $\beta$-catenin in chronic myeloid leukemia through its tyrosine phosphorylation. EMBO J 26: 1456-1466, 2007.

140. Nakayama S, Sng N, Carretero J, Welner R, Hayashi Y, Yamamoto M, Tan AJ, Yamaguchi N, Yasuda H, Li D, et al: $\beta$-catenin contributes to lung tumor development induced by EGFR mutations. Cancer Res 74: 5891-5902, 2014.

141. Kajiguchi T, Katsumi A, Tanizaki R, Kiyoi H and Naoe T: Y654 of $\beta$-catenin is essential for FLT3/ITD-related tyrosine phosphorylation and nuclear localization of $\beta$-catenin. Eur $J$ Haematol 88: 314-320, 2012.

142. Jin B, Ding K and Pan J: Ponatinib induces apoptosis in imatinibresistant human mast cells by dephosphorylating mutant D816V KIT and silencing $\beta$-catenin signaling. Mol Cancer Ther 13: 1217-1230, 2014.

143. Fernández-Sánchez ME, Barbier S, Whitehead J, Béalle G, Michel A, Latorre-Ossa H, Rey C, Fouassier L, Claperon A, Brullé L, et al: Mechanical induction of the tumorigenic $\beta$-catenin pathway by tumour growth pressure. Nature 523: 92-95, 2015.

144.Zhao Y, Masiello D, McMillian M, Nguyen C, Wu Y, Melendez E, Smbatyan G, Kida A, He Y, Teo JL, et al: CBP/ catenin antagonist safely eliminates drug-resistant leukemiainitiating cells. Oncogene 35: 3705-3717, 2016.

145. Smyth MJ, Ngiow SF, Ribas A and Teng MW: Combination cancer immunotherapies tailored to the tumour microenvironment. Nat Rev Clin Oncol 13: 143-158, 2016.

146. Palucka AK and Coussens LM: The basis of oncoimmunology. Cell 164: 1233-1247, 2016.

147. Zarour HM: Reversing T-cell dysfunction and exhaustion in cancer. Clin Cancer Res 22: 1856-1864, 2016.

148. Chen DS and Mellman I: Elements of cancer immunity and the cancer-immune set point. Nature 541: 321-330, 2017.

149. Inman BA, Longo TA, Ramalingam S and Harrison MR: Atezolizumab: A PD-L1-blocking antibody for bladder cancer. Clin Cancer Res 23: 1886-1890, 2017.

150. Kim ES: Avelumab: First global approval. Drugs 77: 929-937, 2017.

151. Syed YY: Durvalumab: First global approval. Drugs 77: 1369-1376, 2017.

152.Zaretsky JM, Garcia-Diaz A, Shin DS, Escuin-Ordinas H, Hugo W, Hu-Lieskovan S, Torrejon DY, Abril-Rodriguez G, Sandoval S, Barthly L, et al: Mutations associated with acquired resistance to PD-1 blockade in melanoma. N Engl J Med 375: 819-829, 2016

153. Shin DS, Zaretsky JM, Escuin-Ordinas H, Garcia-Diaz A, Hu-Lieskovan S, Kalbasi A, Grasso CS, Hugo W, Sandoval S, Torrejon DY, et al: Primary resistance to PD-1 blockade mediated by JAK1/2 mutations. Cancer Discov 7: 188-201, 2017.

154. Anagnostou V, Smith KN, Forde PM, Niknafs N, Bhattacharya R, White J, Zhang T, Adleff V, Phallen J, Wali N, et al: Evolution of neoantigen landscape during immune checkpoint blockade in non-small cell lung cancer. Cancer Discov 7: 264-276, 2017.

155. Huang AC, Postow MA, Orlowski RJ, Mick R, Bengsch B, Manne S, Xu W, Harmon S, Giles JR, Wenz B, et al: T-cell invigoration to tumour burden ratio associated with anti-PD-1 response. Nature 545: 60-65, 2017.

156. Manguso RT, Pope HW, Zimmer MD, Brown FD, Yates KB, Miller BC, Collins NB, Bi K, LaFleur MW, Juneja VR, et al: In vivo CRISPR screening identifies Ptpn2 as a cancer immunotherapy target. Nature 547: 413-418, 2017. 
157.Holtzhausen A, Zhao F, Evans KS, Tsutsui M, Orabona C, Tyler DS and Hanks BA: Melanoma-derived Wnt5a promotes local dendritic-cell expression of IDO and immunotolerance: Opportunities for pharmacologic enhancement of immunotherapy. Cancer Immunol Res 3: 1082-1095, 2015.

158.Hugo W, Zaretsky JM, Sun L, Song C, Moreno BH, Hu-Lieskovan S, Berent-Maoz B, Pang J, Chmielowski B, Cherry G, et al: Genomic and transcriptomic features of response to anti-PD-1 therapy in metastatic melanoma. Cell 165 35-44, 2016.

159. D'Amico L, Mahajan S, Capietto AH, Yang Z, Zamani A, Ricci B, Bumpass DB, Meyer M, Su X, Wang-Gillam A, et al: Dickkopf-related protein 1 (Dkk1) regulates the accumulation and function of myeloid derived suppressor cells in cancer. J Exp Med 213: 827-840, 2016.

160. Fulciniti M, Tassone P, Hideshima T, Vallet S, Nanjappa $P$, Ettenberg SA, Shen Z, Patel N, Tai YT, Chauhan D, et al: Anti-DKK1 mAb (BHQ880) as a potential therapeutic agent for multiple myeloma. Blood 114: 371-379, 2009.

161. Bendell JC, Murphy JE, Mahalingam D, Halmos B, Sirard CA, Landau SB and Ryan DP: A Phase 1 study of DKN-01, an anti-DKK1 antibody, in combination with paclitaxel in patients with DKK1 relapsed or refractory esophageal cancer or gastro-esophageal junction tumors. J Clin Oncol 34 (Suppl 4): S111, 2016. http://ascopubs.org/doi/abs/10.1200/jco.2016.34.4 suppl.111.
162. Camidge DR, Pao W and Sequist LV: Acquired resistance to TKIs in solid tumours: Learning from lung cancer. Nat Rev Clin Oncol 11: 473-481, 2014.

163. Pauli C, Hopkins BD, Prandi D, Shaw R, Fedrizzi T, Sboner A, Sailer V, Augello M, Puca L, Rosati R, et al: Personalized in vitro and in vivo cancer models to guide precision medicine. Cancer Discov 7: 462-477, 2017.

164. Massard C, Michiels S, Ferté C, Le Deley MC, Lacroix L, Hollebecque A, Verlingue L, Ileana E, Rosellini S, Ammari S, et al: High-throughput genomics and clinical outcome in hardto-treat advanced cancers: Results of the MOSCATO 01 trial. Cancer Discov 7: 586-595, 2017.

165. Rheinbay E, Parasuraman P, Grimsby J, Tiao G, Engreitz JM, Kim J, Lawrence MS, Taylor-Weiner A, Rodriguez-Cuevas S, Rosenberg $\mathrm{M}$, et al: Recurrent and functional regulatory mutations in breast cancer. Nature 547: 55-60, 2017

166. van de Wetering M, Francies HE, Francis JM, Bounova G, Iorio F, Pronk A, van Houdt W, van Gorp J, Taylor-Weiner A, Kester L, et al: Prospective derivation of a living organoid biobank of colorectal cancer patients. Cell 161: 933-945, 2015.

167. Merker SR, Weitz J and Stange DE: Gastrointestinal organoids: How they gut it out. Dev Biol 420: 239-250, 2016.

168. Zhang L, Adileh M, Martin ML, Klingler S, White J, Ma X, Howe LR, Brown AM and Kolesnick R: Establishing estrogenresponsive mouse mammary organoids from single Lgr5(+) cells. Cell Signal 29: 41-51, 2017. 